Research Article

\title{
A Record-based Analysis of Profile, Pattern and Outcomes of Geriatric Fractures in a Tertiary Care Hospital, Chandigarh
}

\author{
A Rana', $\underline{\text { A Kumar }}{ }^{2}, \underline{\text { S Sharma }} 3$, Amarjeet Singh ${ }^{4}$ \\ ${ }^{1}$ Project Associate, ${ }^{4}$ Professor \& Head, Community Medicine \& School of Public Health, PGIMER, Chandigarh, India. \\ ${ }^{2}$ Senior Physiotherapist, PGIMER, Chandigarh, India. \\ ${ }^{3}$ Associate Professor, Trauma \& Orthopedics. \\ DOI: https://doi.org/10.24321/2454.325X.202112
}

I $\quad \mathbf{N} \quad \mathbf{F} \quad \mathbf{O}$

\section{Corresponding Author:}

Amarjeet Singh, Community Medicine \& School of Public Health, PGIMER, Chandigarh, India.

dramarjeet56@gmail.com

E-mail Id:

dramarjeet56@gmail.com

Orcid Id:

https://orcid.org/0000-0003-0978-0907

How to cite this article:

Rana A, Kumar A, Sharma S, Singh A. A Recordbased Analysis of Profile, Pattern and Outcomes of Geriatric Fractures in a Tertiary Care Hospital, Chandigarh. Int J Preven Curat Comm Med. 2021;7(3):12-16.

Date of Submission: 2021-08-02

Date of Acceptance: 2021-09-18

\section{$\begin{array}{lllllllll}\mathbf{A} & \mathbf{B} & \mathbf{S} & \mathbf{T} & \mathbf{R} & \mathbf{A} & \mathbf{C} & \mathbf{T}\end{array}$}

Introduction: Older people with diseased conditions are more prone to fracture irrespective of gender. Osteoporosis is the most common cause of elderly fractures.

Objectives: 1) To ascertain the profile and pattern of geriatric fracture cases reporting a tertiary care institution, 2) To ascertain the extent of mortality and complications in geriatric fracture cases, and 3) To ascertain the functional outcomes of geriatric fracture cases discharged from the tertiary care institute.

Methodology: A list of geriatric fracture inpatients of an institution was made for 2014 - 2018. The data on the profile of patients, type of fracture, treatment received, the lag time between the reporting and the surgery, comorbidities, past medical history, cause/ place of fracture, length of stay, and status at the time of the phone-based interview were analysed through SPSS software.

Results: The highest range of the age for fracture occurrence was 60-70 years. Female patients were more than the male ones. Femur fracture was the most common. The most common direct cause of the fracture was fall (indoor). Open reduction, internal fixation and arthroplasty were the commonest treatment performed. The lag time between the patient arrival to the health care and surgery was 0-5 days. The highest length of stay by the patients in the hospital was 0-10 days.

Conclusion: The possible direct causes of the fracture reported in the study were falls, roadside accidents, trauma etc.

Keywords: Elderly Care, Geriatric Friendly Environment, Fracture, Fall, Geriatric Fracture 


\section{Introduction}

As the second populous inhabited country in the world, India is facing a rise in geriatric morbidities. With an increase in the elderly population, fracture has become an area of major concern because of their vulnerability. Fractures constitute a major source of disability, dysfunction, and reduced quality of life in the elderly, leading to high demand for resources, mainly due to a rise in mortality and dependency. Osteoporosis is the most common cause of hip fracture among the elderly. Age, gender, comorbidity, pre-fracture functional status, and fracture type affect the outcome concerning movement, common activities of daily living, and quality of life. The elderly people who sustain hip fractures usually have multiple medical conditions which directly affect their treatment and outcomes. The incidence of geriatric fractures increases with age. With the rise in comorbidities, the problem of fracture among the elderly is becoming more challenging than it was a decade ago. Many of the elderly with fractures report to tertiary care institutions, which can be a major source of information on the type of fracture, complication, treatment modality, and the outcome. Therefore, this study was planned to ascertain the profile and pattern of geriatric fracture cases, to ascertain the extent of mortality and complications in these cases, and to ascertain the functional outcomes of these fracture cases discharged from a tertiary care institute.

\section{Methodology}

This study involved data retrieval from records supplemented by phone-based collection of information on the current status of the patients. It was conducted in a tertiary health care institution, the Post-Graduate Institute of Medical Education \& Research (PGIMER), Chandigarh. A list of geriatric fracture inpatients was made for $2014-2018$. The sample size was calculated as 250 (at Alpha $=0.05$; Beta $=0.80 ; P=0.25 ; Q=0.75)$. A simple random sampling technique was used to select the cases to represent all the years (2014-2018) in both categories (male and female).

For determining the profile/ pattern of the geriatric fracture cases, the data were retrieved and analysed, based on the domains presented at the clinical record data available for the 5 years.

The data collected were stored in an Excel spreadsheet and then it was transferred to SPSS software for analysis to determine hospitalisation, profile of the patient, type of fracture, treatment received, delay in reporting, lag time between the reporting and the surgery, comorbidities associated, past medical history of the patient, immediate cause of fracture, place of fracture, length of stay, mechanism of the fall, present outcomes of the patient, status at the time of the phone-based interview, ADL Scores, and cause of death as recited by the respondent at the time of the phone-based interview.

\section{Inclusion Criterion}

Records of geriatric fracture inpatients for 2014 - 2018.

\section{Exclusion Criteria}

Those cases whose records were incomplete or those who did not agree for a phone-based interview.

All the study results were kept confidential. Permission was taken from the ethical committee to access the records. Consent of the respondents was taken verbally while doing the phone-based study.

\section{Results}

Overall, 250 cases were recruited in the study. Table 1 shows that the frequency of the most common fracture site was femur (60.54\%), frequency of indoor fracture was the highest (72\%), and the highest frequency for the direct cause of the fracture was fall (81.2\%).

Table I.Details of Fractures

\begin{tabular}{|c|c|}
\hline Details of Fractures & Number (\%) \\
\hline \multicolumn{2}{|l|}{ Site of fracture } \\
\hline Femur & $155(60.54)$ \\
\hline Humerus/Shoulder & $35(13.67)$ \\
\hline Tibia-Fibula & $14(5.46)$ \\
\hline $\begin{array}{l}\text { Other sites (hand/ wrist, pelvis- } \\
\text { Acetabulum, Spine, Knee } \\
\text { Forearm bones, Ankle) }\end{array}$ & $52(20.33)$ \\
\hline \multicolumn{2}{|l|}{ Fracture occurrence location } \\
\hline Indoor & $180(72)$ \\
\hline Outdoor & $47(18.8)$ \\
\hline Not mentioned & $23(9.2)$ \\
\hline \multicolumn{2}{|l|}{ Mechanism of fall } \\
\hline Fall from two-wheeler & $15(7.39)$ \\
\hline Fall due to slippage & $7(3.45)$ \\
\hline Fall from height & $6(2.96)$ \\
\hline Fall from stairs & $5(2.46)$ \\
\hline Fall from bed & $3(1.48)$ \\
\hline Fall from chair & $3(1.48)$ \\
\hline Hit by animal & $4(1.97)$ \\
\hline Not mentioned & $160(78.82)$ \\
\hline \multicolumn{2}{|l|}{ Cause of fracture } \\
\hline Fall & $203(81.2)$ \\
\hline Roadside accident & $15(6)$ \\
\hline Trauma & $8(3.2)$ \\
\hline Pathologic & $1(0.4)$ \\
\hline Not mentioned & $23(9.2)$ \\
\hline
\end{tabular}


Table 2.Treatment-related Details

\begin{tabular}{|c|c|}
\hline Treatment-related Details & Number (\%) \\
\hline \multicolumn{2}{|l|}{ Delay in reporting (days) } \\
\hline $0-5$ & $93(37.20)$ \\
\hline $6-10$ & $22(8.80)$ \\
\hline $11-15$ & $14(5.60)$ \\
\hline $16-30$ & $17(6.80)$ \\
\hline 31\& above & $27(10.80)$ \\
\hline Not mentioned & $77(30.80)$ \\
\hline \multicolumn{2}{|l|}{$\begin{array}{l}\text { Time lag between admission and } \\
\text { surgery (days) }\end{array}$} \\
\hline $0-5$ & $85(43.37)$ \\
\hline $6-10$ & $58(29.59)$ \\
\hline $11-15$ & $24(12.24)$ \\
\hline 16 or above & $20(10.20)$ \\
\hline Not mentioned & $9(4.59)$ \\
\hline \multicolumn{2}{|l|}{ Type of treatment given } \\
\hline Arthroplasty & $68(22.01)$ \\
\hline Amputation & $2(0.65)$ \\
\hline Close reduction & 37 (11.97) \\
\hline Open reduction & $66(21.36)$ \\
\hline Internal fixation & $70(22.65)$ \\
\hline External fixation & $3(0.97)$ \\
\hline Conservative & $54(17.48)$ \\
\hline Implant removal & $9(2.98)$ \\
\hline \multicolumn{2}{|l|}{ Length of stay in the hospital (days) } \\
\hline $0-10$ & $102(40.8)$ \\
\hline $11-20$ & $91(36.4)$ \\
\hline $21-30$ & $28(11.2)$ \\
\hline 31 or above & $19(7.6)$ \\
\hline Not available & $10(4)$ \\
\hline
\end{tabular}

Table 2, shows that reporting delay was for 10 days or less in $46 \%$ of the cases, maximum cases had surgery within 10 days of admission (72.96\%), and most cases had a length of stay of 0-20 days (77.2\%).

Table 3, represents that hypertension (35.91\%), diabetes mellitus (25.82\%), and cardiovascular diseases (22.55\%) were the comorbidities present in the fracture patients.

IADL score of $11 \%$ of the patients had severe to moderate functional impairment and most (88.70\%) were fully functional. Gender-wise, among the people who reported for fracture, 139 (55.6\%) were female and 111 (44.4\%) were male. Age-wise, the maximum cases (54.5\%) were represented by the patients of $60-70$ years of age.
Table 3.Comorbidities present in the Fracture Patients

\begin{tabular}{|c|c|}
\hline Comorbidity & Number (\%) \\
\hline Arthritis & $4(1.19)$ \\
\hline Alzhimers & $1(0.30)$ \\
\hline Cardiovascular disease & $76(22.55)$ \\
\hline Asthma & $9(2.67)$ \\
\hline Cirrhosis & $2(0.59)$ \\
\hline Common peroneal nerve palsy & $2(0.59)$ \\
\hline Chronic myeloid leukemia & $1(0.30)$ \\
\hline Cervical spondylitis & $2(0.59)$ \\
\hline Chronic obstructive pulmonary disease & $3(0.89)$ \\
\hline Diabetic neuropathy & $1(0.30)$ \\
\hline Diabetes mellitus & $87(25.82)$ \\
\hline Essential thrombocythemia & $3(0.89)$ \\
\hline Epilepsy & $4(1.19)$ \\
\hline Fatty liver & $3(0.89)$ \\
\hline Hypertension & $121(35.91)$ \\
\hline Thyroid dysfunction & $8(2.37)$ \\
\hline Psychiatric illness & $4(1.19)$ \\
\hline Scoliosis & $1(0.30)$ \\
\hline TB & $5(1.48)$ \\
\hline
\end{tabular}

*There were multiple responses.

\section{Discussion}

Hip fractures have become a serious cause of health care concern for the elderly population in most countries with increased longevity. ${ }^{7}$ The possible direct causes of the fracture reported in the study were falls, roadside accidents, trauma etc. The highest frequency was of fall (81.2\%). This was reported in other studies also. ${ }^{8}$

The most common location of fracture was indoors (72\%). The outdoor fall accounted for $18.8 \%$ of cases in this study. The architectural design of the house and the facilities available inside can be a major risk for elderly falls. Slippery and highly polished stairs, lack of handhold windows and balconies (low or no grills), high racks and cupboards, absence of ramps, slippery bathroom floors, and tripping on rugs in the house can be major risks for indoor falls. Environmental and genetic factors play a role in the aetiology of hip fracture. ${ }^{9}$ The various risk factors which contribute to the falls among elderly are environmental hazards, unsafe indoor and outdoor areas, various drug interactions, drowsiness, confusion, heart failure, urinary incontinence, arthritis, cataract, and Parkinson's disease. ${ }^{10}$

The mechanism of the fall mentioned in the study included fall from bed, two-wheelers, chairs, stairs, heights, hit by 
animals, slippage or trauma from road accidents. Roadside accidents and accidental falls are becoming more common due to unsafe roads and outer environments for the elderly, low vision, poor gait, and hearing problems.

Multiple treatment modalities were seen in the study, e.g., arthroplasty (22.01\%), open reduction (21.36\%), internal fixation (22.65\%), external fixation, close reduction, conservative treatment, and implant removal. The frequency of the conservative treatment was as high as $17.48 \%$ in this study, e.g., repositioning of the fractured bone by manipulating it through the skin followed by immobilisation of the bone with the help of the cast for several weeks followed by a series of physiotherapy sessions. In most cases, the fractures were immobilised, stabilised, and realigned with traction before surgery. Internal and external fixation of rods or pins was used to hold the bone in place to allow the bones to align.

Pre-existing morbidities affect fracture susceptibility and the outcomes in an older adult. Osteoporosis is the most common cause of fractures in the elderly and the burden of osteoporosis will increase in the coming years because of the ageing population. ${ }^{11}$

The conservative treatment was indicated in the patients who had manageable fractures and the ones in whom surgeries were contraindicated due to comorbidities such as hypertension, diabetes mellitus, cardiovascular diseases, chronic kidney diseases etc. Comorbidities have been documented as the major preoperative risk factor for the elderly. ${ }^{12}$

The timing of surgery plays an important role in the survival and post-operative treatment outcomes. The early presentation has better prognosis rehabilitation with facilitation for return to work and independence. ${ }^{13,14}$ The delay in surgery was seen more in patients having more than one co-morbidities. The stabilisation of the patient and the pre-anaesthetic clearance from different departments is one factor for the delay. Patients with more than 48 hours of delay have been documented to have an overall increase in postoperative complications. ${ }^{15-16}$ The lag between the admission and the surgery for patients was within 1-10 days $(72.96 \%)$. This shows that the institute delivers the service without much delay.

The maximum length of hospital stay was of 0-20 days (77.2\%). A prolonged stay at the hospital not only increases the risk of hospital-acquired infections but also constraints the bed availability for new patients.

Majority (67.2\%) of the respondents were alive with most of them (81.56\%) having an ADL score $>6$. About one third (32.74\%) died due to unsuccessful operation (10.81\%), refractures $(5.41 \%)$, old age (16.22\%), comorbidity $(8.11 \%)$, multiple organ failure $(2.70 \%)$, heart failure $(8.11 \%)$, internal bleeding $(2.70 \%)$, renal failure $(5.41 \%)$, loss of interest in living $(10.81 \%)$, health deterioration after fracture (18.92\%), cancer $(2.70 \%)$, cardiac issues $(2.7 \%)$, and some unknown reasons $(5.41 \%)$. Chest infection and heart failure are the most common postoperative complications which may lead to increased mortality. ${ }^{9,12,17,18}$

\section{Conclusion}

The highest age range for fracture occurrence was 60-70 years in the study. Female patients were more than male patients. Femur fracture was the most common. The most common direct cause of the fracture was fall (indoor). The most common comorbidities seen in the past medical history of the fracture patients were hypertension, diabetes mellitus, or cardiovascular diseases. Open reduction, internal fixation, and arthroplasty were the commonest treatment performed. The highest delay in reporting was $0-5$ days. The highest lag time between the patient arrival to the health care and surgery was 0-5 days. The highest length of stay by the patients in the hospital was 0-10 days. At the time of the interview, the majority of the respondents were alive (67.26\%) and fully functional.

\section{Recommendations}

There is a need to build geriatric friendly houses which are fall-free with non-slippery floors, rest areas, ramps, and easily approachable cabinets for various daily activities by the elders. Making elderly-friendly roads and streets, places to rest, a secure environment, and green spaces can help older adults have a more active lifestyle. Early reporting of patients to the medical facility after the fracture can improve postoperative outcomes.

\section{Source of Funding: None}

Conflict of Interest: None

\section{References}

1. Cooper C, Campion G, Melton 3rd LJ. Hip fractures in the elderly: a world-wide projection. Osteoporos Int. 1992;2(6):285-9. [PubMed] [Google Scholar]

2. Jordan KM, Cooper C. Epidemiology of osteoporosis. Best Pract Res Clin Rheumatol. 2002;16(5):795-806. [PubMed] [Google Scholar]

3. Mithal A, Bansal B, Kyer CS, Ebeling P. The Asia-Pacific Regional Audit-epidemiology, costs, and burden of osteoporosis in India 2013: a report of International Osteoporosis Foundation. Indian J Endocrinol Metab. 2014;18(4):449. [PubMed] [Google Scholar]

4. Roth T, Kammerlander C, Gosch M, Luger TJ, Blauth $M$. Outcome in geriatric fracture patients and how it can be improved. Osteoporos Int. 2010;21(4):615-9. [PubMed] [Google Scholar]

5. Menzies IB, Mendelson DA, Kates SL, Friedman SM. The impact of comorbidity on perioperative outcomes 
of hip fractures in a geriatric fracture model. Geriatr Orthop Surg Rehabil. 2012 Sep;3(3):129-34. [PubMed] [Google Scholar]

6. Rath S, Yadav L, Tewari A, Chantler T, Woodward M, Kotwal P, Jain A, Dey A, Garg B, Malhotra R, Goel A, Farooque K, Sharma V, Webster P, Norton R. Management of older adults with hip fractures in India: a mixed-methods study of current practice, barriers and facilitators, with recommendations to improve care pathways. Arch Osteoporos. 2017 Dec;12(1):55. [PubMed] [Google Scholar]

7. Bishnoi M, Kirmani TT, Huda N, Chahal G, Bishnoi S. Epidemiological analysis of hip fractures at a tertiary care centre: a retrospective study. Int J Res Orthop. 2018;4(4):568-71. [Google Scholar]

8. Al-Aama T. Falls in the elderly: spectrum and prevention. Can Fam Physician. 2011 Jul;57(7):771-6. [PubMed] [Google Scholar]

9. Dhanwal DK, Dennison EM, Harvey NC, Cooper C. Epidemiology of hip fracture: worldwide geographic variation. Indian J Orthop. 2011;45(1):15-22. [PubMed] [Google Scholar]

10. Berg RL, Cassells JS. Falls in older persons: risk factors and prevention. In: The second fifty years: promoting health and preventing disability. United States: National Academies Press; 1992. [Google Scholar]

11. Graf $C$. The Lawton instrumental activities of daily living (IADL) scale. Medsurg Nurs. 2009;18(5):315-6. [PubMed]

12. Roche JJ, Wenn RT, Sahota O, Moran CG. Effect of comorbidities and postoperative complications on mortality after hip fracture in elderly people: prospective observational cohort study. BMJ. 2005;331(7529):1374. [PubMed] [Google Scholar]

13. Dash SK, Panigrahi R, Palo N, Priyadarshi A, Biswal M. Fragility hip fractures in elderly patients in Bhubaneswar, India (2012-2014): a prospective multicenter study of 1031 elderly patients. Geriatr Orthop Surg Rehabil. 2015;6(1):11-5. [PubMed] [Google Scholar]

14. Safer MA, Tharps QJ, Jackson TC, Leventhal H. Determinants of three stages of delay in seeking care at a medical clinic. Med Care. 1979 Jan;17(1):11-29. [PubMed] [Google Scholar]

15. Wei J, Zeng L, Li S, Luo F, Xiang Z, Ding Q. Relationship between co-morbidities and treatment decision-making in elderly hip fracture patients. Aging Clin Exp Res. 2019 Apr16;31:1375-41. [Google Scholar]

16. Bennett A, Li H, Patel A, Kang K, Gupta P, Choueka J, Feierman DE. Retrospective analysis of geriatric patients undergoing hip fracture surgery: delaying surgery is associated with increased morbidity, mortality, and length of stay. Geriatric Orthop Surg Rehabil. 2018 Sep;9:2151459318795260. [PubMed] [Google Scholar]
17. Frost SA, Nguyen ND, Black DA, Eisman JA, Nguyen TV. Risk factors for in-hospital post-hip fracture mortality. Bone. 2011 Sep;49(3):553-8. [PubMed] [Google Scholar]

18. Chrispal A, Mathews KP, Surekha V. The clinical profile and association of delirium in geriatric patients with hip fractures in a tertiary care hospital in India. J Assoc Physicians India. 2010 Jan;58:15-9. [PubMed] [Google Scholar] 